\title{
Localized Reactive Power Markets Using the Concept of Voltage Control Areas
}

\author{
Jin Zhong, Student Member, IEEE, Emilia Nobile, Member, IEEE, Anjan Bose, Fellow, IEEE, and \\ Kankar Bhattacharya, Senior Member, IEEE
}

\begin{abstract}
In this paper, we present the design of a localized competitive market for reactive power ancillary services at the level of individual voltage-control areas. The concept of electrical distance has been used to identify the different voltage-control areas within a power system. The proposed reactive power market is settled on uniform price auction, using a modified optimal power-flow model. Uniform prices for various components of reactive power service are obtained for each voltage-control area. In the study cases described in the paper, we examine whether such a localized reactive power market is more desirable than a common system-wide reactive power market.
\end{abstract}

Index Terms-Ancillary services, deregulation, market design, reactive power, voltage-control areas.

\section{NOMENCLATURE}

$i, j \quad$ Index for buses.

$n \quad$ Total bus number of a system.

gen Index for generator at a bus.

$\mathrm{PG}^{\text {Con }}$ Contracted real power generation, p.u.

$\mathrm{XP}^{\text {con }} \quad$ Contracted real power transaction between a load and a generator.

XP Actual real power transaction allowed by ISO, p.u.

Q Reactive power support at a bus, p.u.

QD Reactive power demand at a bus, p.u.

QC Reactive support from shunt capacitors at a bus, p.u.

V Voltage at a bus, p.u.

Y Element of network admittance matrix, p.u.

$\theta \quad$ Angle associated with $\mathrm{Y}$, radians.

\section{INTRODUCTION}

I T HAS BEEN generally recognized now by several power system operators in different countries that in deregulated electricity markets, the provision for reactive power should be handled as an ancillary service. And that there is a need to device appropriate payment mechanisms for such services. Some of the markets have already established these mechanisms, such as

Manuscript received November 19, 2003. This work was supported by Sydkraft Research Foundation of Sydkraft AB, Sweden, as part of the research project on ancillary services.

J. Zhong is with the Department of Electric Power Engineering, Chalmers University of Technology, S-41296 Gothenburg, Sweden.

E. Nobile is with Shaw Power Technologies International, European Office, Knutsford, U.K.

A. Bose is with the School of Electrical Engineering and Computer Science, Washington State University, Pullman, WA 99164 USA.

K. Bhattacharya is with the Department of Electrical and Computer Engineering, University of Waterloo, Waterloo, ON N2L 3G1, Canada.

Digital Object Identifier 10.1109/TPWRS.2004.831656 the New York Independent System Operator (ISO) which uses an embedded cost based method [1] or the National Electricity Market Management Company (NEMMCO) of Australia where payment for reactive power support is admissible to both generators and synchronous condensers and comprise three components: availability, enabling, and compensation [2]. On the other hand, the deregulated markets in the Nordic countries however, have no provision for payment for reactive power services. The responsibility for managing reactive power lies with regional and local network companies [3]. A review of reactive power management practices adopted in some of the deregulated electricity markets around the world has been presented in [4].

Attempt is being made by researchers to capture various issues in reactive power management in the context of the new operating paradigms in deregulated power systems. The technical and economic issues involved in determining reactive power prices in a deregulated market were discussed in [5]. In earlier works by the authors [6], a framework for optimal procurement of reactive power services was developed. It was demonstrated that the classical objective function of loss minimization, used for reactive power optimization problems, was no longer sufficient in deregulated markets and needed to be appropriately modified. Subsequently in [7] the authors presented a uniform price auction model to competitively determine the prices for different components of reactive power service, namely, availability, operating, and opportunity.

A uniform price for each of these components was calculated and all selected reactive power providers, irrespective of their location, received those prices. The scheme provided a fair method to determine the prices for reactive power service in a competitive market environment. However, under certain system configuration and load flow condition, it was observed that some providers could hold market power and if they indulged in gaming, could alter the market prices to their advantage. Such a situation is undesirable for an efficient and competitive market.

In order to address the above issue, we now examine the possibility of constructing a localized reactive power payment mechanisms within the same competitive reactive power market framework presented in [7]. We propose a "differential payment" scheme to the reactive power providers based on their location in the system and consequently the "worth" of their reactive power service. Such a localized and differential payment mechanism provides a fair competition for those service providers that are located at "nonstrategic" nodes.

In this paper, we examine the possibility of designing a localized reactive power market for individual voltage-control 
areas in a power system. Since reactive power and voltage-control services are required to be provided locally, the reactive power market can be considered more as a local market than a system-wide market. A local market structure, with a reactive power price for each local area, is thus proposed and is described in the following sections.

In Section II the concept of electrical distance has been used to identify different voltage-control areas in a given power system. In Section III, a new payment objective function has been formulated in order to obtain the individual area-wise uniform prices for reactive power services. In Section IV, a case study with the Cigré 32-bus system has been presented, wherein the system is separated into three voltage-control areas and the uniform reactive power market prices are obtained for each area respectively.

\section{IDENTIFying Voltage-CONTROL AREAS IN A SYSTEM}

A given power system can be separated into some nonoverlapping voltage-control areas comprising coherent bus groups. A set of buses can be classified as a voltage-control area if they are sufficiently uncoupled electrically, from its neighboring areas. And the controllable reactive power in the area should be enough to master the voltage changes at the buses in the area. A criterion for separating voltage-control areas, as per [8], is that the voltage profile of one control area is mainly controlled by the reactive power sources in that area, and the controls within the area are very less influenced by other areas.

A two-stage systematic method reported in [9] has proved effective for determining voltage-control areas in the French power system. The first stage involves calculating the electrical distance between the buses in the system. The second stage is to group the buses following the topological analysis methods. In [10], the above concept has been used to analyze "local" voltage stability problems and assess voltage security, while it has been used for examining localized voltage-control services in [11].

In this paper, the voltage-control areas for a system are identified following the method described in [9] in two steps:

1) calculate electrical distance between all nodes in the system;

2) using hierarchical classification algorithm classify the areas and decide the borders of each areas.

\section{A. Electrical Distance}

The concept of electrical distance [9] involves the matrix $[\partial \mathbf{Q} / \partial \mathbf{V}]$ which is a part of the Jacobian matrix $\mathbf{J}$, and its inverse $[\partial \mathbf{V} / \partial \mathbf{Q}]$, called the sensitivity matrix. Both matrices are real and nonsymmetrical. The elements of $[\partial \mathbf{V} / \partial \mathbf{Q}]$ reflect the propagation of voltage variation following reactive power injection at a bus. The magnitude of voltage coupling between two buses can be quantified by the maximum attenuation of voltage variation between these two buses. These attenuations are easy to obtain from the $[\partial \mathbf{V} / \partial \mathbf{Q}]$ matrix, by just dividing the elements of each column by the diagonal term. A matrix of attenuations between all the buses of the system, whose terms are written as $\alpha_{\mathrm{ij}}$ is then available. We thus have

$$
\Delta V_{i}=\alpha_{i j} \Delta V_{j}
$$

where

$$
\alpha_{i j}=\left(\frac{\partial V_{i}}{\partial Q_{j}}\right) /\left(\frac{\partial V_{j}}{\partial Q_{j}}\right) .
$$

Generally, $\alpha_{\mathrm{ij}} \neq \alpha_{\mathrm{ji}}$. In order to have symmetric property in the electrical distance, the formulation below is used to define the electrical distance between two nodes $i$ and $j$ [9]

$$
D_{i j}=D_{j i}=-\log \left(\alpha_{i j} \cdot \alpha_{j i}\right)
$$

$\mathrm{D}_{\mathrm{ij}}$ is the electrical distance between node $i$ and $j$, and it has the properties of positivity and symmetry. This electrical distance can represent the degree of influence arising from voltage changes on other buses. The step-by-step method to obtain the separate voltage-control areas is given as follows.

1) Calculate the Jacobian matrix $J$ and hence obtain the submatrix $\mathrm{J}_{4}$, where $J_{4}=[\partial \mathbf{Q} / \partial \mathbf{V}]$.

2) Invert $\mathrm{J}_{4}$. Say, $B=(\partial V / \partial Q)=J_{4}^{-1}$, and the elements of matrix $\mathrm{B}$ are written as $\mathrm{b}_{\mathrm{ij}}$, where $b_{i j}=\partial V_{i} / \partial Q_{j}$.

3) Obtain attenuation matrix, $\alpha_{\mathrm{ij}}$, between all the nodes as follows: $\alpha_{\mathrm{ij}}=\mathrm{b}_{\mathrm{ij}} / \mathrm{b}_{\mathrm{jj}}$.

4) Calculate electrical distances $D_{i j}$

$$
\mathrm{D}_{\mathrm{ij}}=-\log \left(\alpha_{\mathrm{ij}}, \alpha_{\mathrm{ji}}\right)
$$

5) Normalize the electrical distances as follows:

$$
\mathrm{D}_{\mathrm{ij}}=\mathrm{D}_{\mathrm{ij}} / \operatorname{Max}\left(\mathrm{D}_{\mathrm{i} 1}, \ldots, \mathrm{D}_{\mathrm{iN}}\right)
$$

In practice, instead of $[\partial \mathbf{Q} / \partial \mathbf{V}]$, the susceptance matrix $B$ " can be used.

\section{B. Determining Zones According to Electrical Distance}

Once the electrical distances for any couple of nodes in the system are defined, it is possible to trace the boundary of the voltage-control areas [11]. There is no unique way to do so; the general idea is to give autonomy and independence, from a reactive power management standpoint, to each area. This is accomplished in different ways depending on the power system.

In this paper, we use a hierarchical classification algorithm to determine the zones according to the electrical distances calculated using the five steps described in Section II-A.

For each generator bus "i", its nominal electrical distances to other buses " $\mathrm{j}$ " $(\mathrm{j} \in \mathrm{n}, \mathrm{j} \neq \mathrm{i}), \mathrm{D}_{\mathrm{ij}}$, are classified into some ranges, Range1, Range 2 , Range $3, . .$. , which are in an ascending order. The relationships between them can be expressed as follows:

$$
\begin{aligned}
0 & \leq \text { Range } 1<R_{1} \\
R_{1} & \leq \text { Range } 2<R_{2} \\
R_{2} & \leq \text { Range } 3<R_{3} \ldots \\
R_{1} & <R_{2}<R_{3}<\ldots
\end{aligned}
$$

Then, we start from Range1. For each bus “j” whose distance to generator " $i$ " is shorter than $R_{1}$, i.e., $D_{i j} \in$ Range 1 , the bus will be put in the same group as generator "i". This grouping step is repeated to all the generator buses for Range1. If there are still some buses being out of any group, we can repeat the grouping steps for Range 2 , Range $3, .$. , until all the buses are at 
least in one of the groups. The smaller the ranges, the better the grouping effects will be. There may be a few overlaps between groups, in other words, there may be a few buses belong to more than one groups. For this case, according to its electrical distance to other buses, a simple judgment can be done to classify it to one of the groups. So far, the voltage-control areas and their borders can be determined. In the case study of Section IV-A, this hierarchical method is used to separate voltage-control areas for Cigré 32-bus system.

\section{Reactive Power Market in Local VOLTAGE-CONTROL AREAS}

In this model, the reactive power market is settled at the level of individual voltage-control areas. All market participants within a voltage-control area submit their offers to the ISO in terms of the four components as discussed in [7]. For the sake of continuity and convenience of the readers, we discuss in Section III-A the reactive power offer structure developed in [7] again. The reactive power market settlement model for individual voltage-control areas is discussed in Section III-B.

\section{A. Structure of Reactive Power Offers}

In this section, we briefly describe the four component offer structure used in this paper. A detailed discussion of this offer price structure can be found in the authors' earlier paper [6].

Based on the classification of reactive power production costs, a generalized expected payment function (EPF) and hence an offer structure can be formulated mathematically as given follows:

$$
\begin{aligned}
\mathrm{EPF}_{\mathrm{i}}=a_{\mathrm{o}, \mathrm{i}}+\int_{\mathrm{Q}_{\mathrm{Min}}}^{0} m_{1 \mathrm{i}} \cdot \mathrm{dQ}_{\mathrm{i}}+\int_{\mathrm{Qbase}_{\mathrm{b}}}^{Q_{\mathrm{A}}} \mathrm{m}_{2 \mathrm{i}} \\
\cdot \mathrm{dQ}_{\mathrm{i}}+\int_{\mathrm{Q}_{\mathrm{A}}}^{\mathrm{Q}_{\mathrm{B}}}\left(\mathrm{m}_{3 \mathrm{i}} \cdot \mathrm{Q}_{\mathrm{i}}\right) \cdot \mathrm{dQ}_{\mathrm{i}} \cdot
\end{aligned}
$$

The coefficients in (3) represent the various components of reactive power cost incurred by provider $i$ that need to be offered in the market. These are explained as follows.

$a_{o} \quad$ Availability price offer, in $\$$.

$\mathrm{m}_{1} \quad$ Operating price offer for operating in under-excited mode (absorb reactive power), $\mathrm{Q}_{\mathrm{Min}} \leq \mathrm{Q} \leq 0$, \$/MVArh.

$\mathrm{m}_{2} \quad$ Operating price offer for operating in the region $\mathrm{Q}_{\text {Base }} \leq \mathrm{Q} \leq \mathrm{Q}_{\mathrm{A}}$, \$/MVArh.

$\mathrm{m}_{3} \mathrm{Q}$ Opportunity price offer for operating in the region $\mathrm{Q}_{\mathrm{A}} \leq \mathrm{Q} \leq \mathrm{Q}_{\mathrm{B}},(\$ / M V A r h) / M V A r h$. Note that the opportunity offer is a function of reactive power output and hence the corresponding EPF component will be a quadratic function of $\mathrm{Q}$.

The generalized EPF vis-à-vis the offer parameters, discussed above, are shown in Fig. 1. $Q_{\min }$ is the lower limit of reactive power generation. $Q_{\text {base }}$ is the reactive power required by a generator for its auxiliary equipment. Production in the region $\left(0, Q_{\text {base }}\right)$ is not entitled to receive any payment.

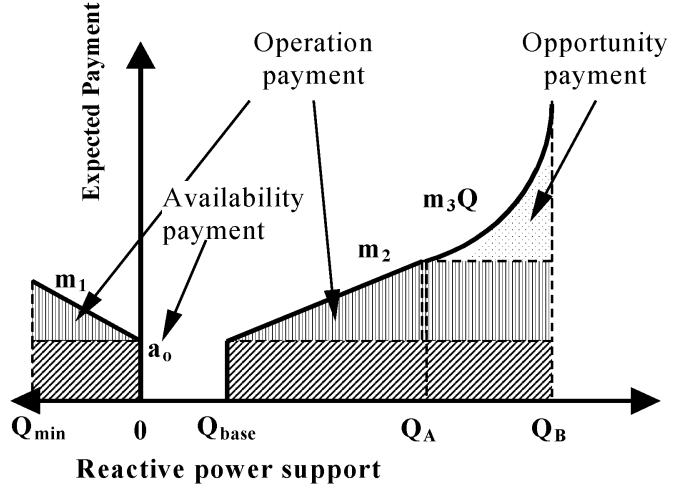

Fig. 1. Structure of reactive offers from providers.

In the market model to be discussed next, all the market participants submit their reactive power offers in terms of the four components, the availability offer $a_{0}$, the operating offer $m_{1}$ and $\mathrm{m}_{2}$, and opportunity offer $\mathrm{m}_{3}$.

\section{B. Market Settlement in Voltage-Control Areas}

1) Objective Function: A payment function is developed and discussed here, that seeks the uniform reactive power market price in individual voltage-control areas. Suppose we have three voltage-control areas, Zone A, Zone B, and Zone C, with respective uniform market prices $\rho_{\mathrm{a}}, \rho_{\mathrm{b}}$, and $\rho_{\mathrm{c}}$, for each area. The subscripts "gen,a", "gen,b" and "gen,c" denote the generators in Zone A, Zone B, and Zone C, respectively. Thus, we can write the payment objective function based on zonal reactive power prices as follows:

$$
\begin{aligned}
J_{\text {Payment }}= & \sum_{\text {gen }}\left(\rho_{0} \cdot W_{0, \text { gen }}-\rho_{1} \cdot W_{1, \text { gen }} \cdot Q_{1, \text { gen }}\right) \\
& +\sum_{\text {gen }, a}\left(\rho_{2 a} \cdot W_{2, \text { gen } a} \cdot Q_{2, \text { gen } a}+\rho_{2 a} \cdot W_{3, \text { gen } a}\right. \\
& \left.\cdot Q_{A, \text { gen } a}+\frac{1}{2} \rho_{3 a} \cdot W_{3, \text { gen } a} \cdot Q_{3, \text { gen } a}^{2}\right) \\
& +\sum_{\operatorname{gen}, b}\left(\rho_{2 b} \cdot W_{2, \operatorname{gen} b} \cdot Q_{2, \operatorname{gen} b}+\rho_{2 b} \cdot W_{3, \operatorname{gen} b}\right. \\
& \left.\cdot Q_{A, \operatorname{gen} b}+\frac{1}{2} \rho_{3 b} \cdot W_{3, \operatorname{gen} b} \cdot Q_{3, \operatorname{gen} b}^{2}\right) \\
& +\sum_{\operatorname{gen}, c}\left(\rho_{2 c} \cdot W_{2, \text { gen } c} \cdot Q_{2, \operatorname{gen} c}+\rho_{2 c} \cdot W_{3, \text { gen } c}\right. \\
& \left.\cdot Q_{A, \text { gen } c}+\frac{1}{2} \rho_{3 c} \cdot W_{3, \text { gen } c} \cdot Q_{3, \operatorname{gen} c}^{2}\right) .
\end{aligned}
$$

In (4), $\rho_{0}$ is the uniform availability price for the whole system; $\rho_{1}$ is the uniform operating price for absorbing reactive power; $\rho_{2 a}, \rho_{2 b}$, and $\rho_{2 c}$ are the uniform operating prices for producing reactive power in zone $\mathrm{A}$, zone $\mathrm{B}$, and zone $\mathrm{C}$, respectively; $\rho_{3 a}, \rho_{3 b}$, and $\rho_{3 c}$ are the uniform opportunity prices for zone $\mathrm{A}$, zone $\mathrm{B}$, and zone $\mathrm{C}$ providers, respectively. $\mathrm{Q}_{1}$ is the reactive power in the region $\left(\mathrm{Q}_{\min }, 0\right), \mathrm{Q}_{2}$ in the reactive power in the region $\left(\mathrm{Q}_{\text {base }}, \mathrm{Q}_{\mathrm{A}}\right)$, and $\mathrm{Q}_{3}$ is the reactive power in the region $\left(\mathrm{Q}_{\mathrm{A}}, \mathrm{Q}_{\mathrm{B}}\right) . \mathrm{W}_{1}, \mathrm{~W}_{2}$, and $\mathrm{W}_{3}$ are the binary variables associated with $\mathrm{Q}_{1}, \mathrm{Q}_{2}$ and $\mathrm{Q}_{3}$ to determine if the generator is selected to provide reactive power in the three 
regions discussed above. For example, if $\mathrm{W}_{1, \mathrm{i}}=1$, generator $i$ is selected to provide reactive power in region $\left(\mathrm{Q}_{\min }, 0\right)$.

2) Constraints: The constraints associated with the localized reactive power market settlement problem are listed below.

- Load Flow Equations:

$$
\begin{aligned}
\mathrm{PG}_{\mathrm{i}}^{\text {con }}-\sum_{\text {gen }} \mathrm{XP}_{\mathrm{i}, \text { gen }} & =\sum_{\mathrm{j}} \mathrm{V}_{\mathrm{i}} \mathrm{V}_{\mathrm{j}} \mathrm{Y}_{\mathrm{ij}} \cos \left(\theta_{\mathrm{ij}}+\delta_{\mathrm{j}}-\delta_{\mathrm{i}}\right) \\
\mathrm{Q}_{\mathrm{i}}-\mathrm{QD}_{\mathrm{i}}+\mathrm{QC}_{\mathrm{i}} & =-\sum_{\mathrm{j}} \mathrm{V}_{\mathrm{i}} \mathrm{V}_{\mathrm{j}} \mathrm{Y}_{\mathrm{ij}} \sin \left(\theta_{\mathrm{ij}}+\delta_{\mathrm{j}}-\delta_{\mathrm{i}}\right) .
\end{aligned}
$$

\section{- Reactive Power Relational Constraints and Limits:}

As per the reactive power offer regions, discussed earlier, a set of governing algebraic relations are required to ensure appropriate allocation. These can be written as follows:

$$
\begin{aligned}
& \mathrm{Q}_{\mathrm{i}}=\mathrm{Q}_{1 \mathrm{i}}+\mathrm{Q}_{2 \mathrm{i}}+\mathrm{Q}_{3 \mathrm{i}} \\
& \mathrm{W}_{1 \mathrm{i}} \cdot \mathrm{Q}_{\mathrm{Min}, \mathrm{i}} \leq \mathrm{Q}_{1 \mathrm{i}} \leq \mathrm{W}_{1 \mathrm{i}} \cdot \mathrm{Q}_{\mathrm{base}, \mathrm{i}} \\
& \mathrm{W}_{2 \mathrm{i}} \cdot \mathrm{Q}_{\mathrm{base}, \mathrm{i}} \leq \mathrm{Q}_{2 \mathrm{i}} \leq \mathrm{W}_{2 \mathrm{i}} \cdot \mathrm{Q}_{\mathrm{Ai}} \\
& \mathrm{W}_{3 \mathrm{i}} \cdot \mathrm{Q}_{\mathrm{A}, \mathrm{i}} \leq \mathrm{Q}_{3, \mathrm{i}} \leq \mathrm{W}_{3 \mathrm{i}} \cdot \mathrm{Q}_{\mathrm{Bi}} \\
& W_{1, i}+W_{2, i}+W_{3, i} \leq 1 .
\end{aligned}
$$

\section{- Determining the Market Prices:}

The market prices are determined separately for each component of reactive power. The following constraints ensure that the market price, for a given set of offers, is the highest priced offer accepted:

$$
\begin{aligned}
& \mathrm{W}_{0, \mathrm{i}}=\mathrm{W}_{1, \mathrm{i}}+\mathrm{W}_{2, \mathrm{i}}+\mathrm{W}_{3, \mathrm{i}} \quad \forall \mathrm{i} \in \text { gen } \\
& \mathrm{W}_{0, \mathrm{i}} \cdot \mathrm{a}_{\mathrm{o}, \mathrm{i}} \leq \rho_{\mathrm{o}} \\
& \mathrm{W}_{1, \mathrm{i}} \cdot \mathrm{m}_{1, \mathrm{i}} \leq \rho_{1} \\
& \left(W_{2, i}+W_{3, i}\right) \cdot m_{2, i} \leq \rho_{2 a}, \quad \forall i \in \text { Zone A } \\
& \left(W_{2, i}+W_{3, i}\right) \cdot m_{2, i} \leq \rho_{2 b}, \quad \forall i \in \text { Zone B } \\
& \left(W_{2, i}+W_{3, i}\right) \cdot m_{2, i} \leq \rho_{2 c}, \quad \forall i \in \text { Zone C } \\
& W_{3, i} \cdot m_{3, i} \leq \rho_{3 a}, \quad \forall i \in \text { Zone A } \\
& W_{3, i} \cdot m_{3, i} \leq \rho_{3 b}, \quad \forall i \in \text { Zone B } \\
& W_{3, i} \cdot m_{3, i} \leq \rho_{3 c}, \quad \forall i \in \text { Zone C. }
\end{aligned}
$$

- Reactive Power Generation Limits:

$$
\begin{aligned}
Q_{\mathrm{Min}, i} & \leq Q_{i} \leq Q_{B, i} \\
Q C_{\mathrm{Min}, i} & \leq Q C_{i} \leq Q C_{\max , i .}
\end{aligned}
$$

\begin{tabular}{|c|c|c|c|c|}
\hline \multirow[t]{2}{*}{ Gen } & \multicolumn{4}{|c|}{$\begin{array}{l}\text { Buses having electrical distances in the given range with the } \\
\text { corresponding generator bus }\end{array}$} \\
\hline & $\mathrm{D}_{\mathrm{ij}} \leq 0.10$ & $0.10<\mathrm{D}_{\mathrm{ij}} \leq 0.20$ & $0.20<\mathrm{D}_{\mathrm{ij}} \leq 0.25$ & $0.25<D_{i j} \leq 0.30$ \\
\hline 4072 & 4071 & & 4012 & 1012 \\
\hline 4071 & 4072 & 4012 & 1012 & \\
\hline 4012 & 1012 & 4022 & 4071,1014 & 4072,1022 \\
\hline 4021 & & 4042,4032 & 4031 & 4044 \\
\hline 4031 & & $\begin{array}{l}4041,4022 \\
4032,2031\end{array}$ & & $4021,2032,1022$ \\
\hline 4042 & & $\begin{array}{l}4021,4032 \\
4043,4044\end{array}$ & 4046,1044 & $4031,4045,4047$ \\
\hline 4041 & & 4031,4061 & 4044 & $\begin{array}{l}4062,4032, \\
2031,1044\end{array}$ \\
\hline 4062 & 4063,4061 & & 4041,4045 & 1045 \\
\hline 4063 & 4062 & 4061 & & 4041,4045 \\
\hline 4051 & & 4045,1045 & 4044 & 1041,1044 \\
\hline 4047 & 4046 & 4043 & 4042,4044 & 1044 \\
\hline 2032 & & 2031 & 4031 & \\
\hline 1013 & 1014 & 1011,1012 & 4012 & \\
\hline 1012 & 4012 & 1014 & 1013 & 4071,4022 \\
\hline 1014 & 1013 & $\begin{array}{l}4012,1012, \\
1011\end{array}$ & & \\
\hline 1022 & 4022 & 1021 & & 4031 \\
\hline 1021 & & 1022 & 4022 & \\
\hline 1043 & 1041 & $\begin{array}{l}4044,1044, \\
1045 \\
\end{array}$ & 1042,4045 & 4043 \\
\hline 1042 & & $\begin{array}{l}4044,1044, \\
1045\end{array}$ & $\begin{array}{l}1043,1042 \\
4045\end{array}$ & \\
\hline
\end{tabular}

In (19), the upper limit on reactive power output from a generator is $\mathrm{Q}_{\mathrm{B}}$ (refer to Fig. 1), which takes into account the opportunity component. QC in (20) is the reactive power support from other reactive sources, e.g., capacitor banks. These are not included in the competitive market settlement since, to date, they are not considered ancillary services in most countries.

- Bus Voltage Limits:

$$
\begin{aligned}
\mathrm{V}_{\mathrm{i}}^{\mathrm{Min}} & \leq \mathrm{V}_{\mathrm{i}} \leq \mathrm{V}_{\mathrm{i}}^{\mathrm{Max}} \quad \forall \mathrm{i} \in \text { load bus } \\
\left|\mathrm{V}_{\mathrm{i}}\right| & =\text { constant } \quad \forall \mathrm{i} \in \mathrm{PV} \text { bus }
\end{aligned}
$$

\section{- Limit on Bilateral Transactions:}

TABLE I

Electrical Distances for Grouping Buses in Voltage-Control AREAS

This constraint ensures that all bilateral transactions are within pre-specified limits. The bilateral transactions are modeled using the method discussed in [12]

$$
0 \leq \mathrm{XP}_{\mathrm{i}, \text { gen }} \leq \mathrm{XP}_{\mathrm{i} \text {,gen }}^{\text {con }} \text {. }
$$

\section{Case Study With Cigré 32 Bus System}

The Cigré 32-bus test system is used here to analyze the localized reactive power market considering separate voltage-control areas.

\section{A. Separating Voltage-Control Areas for Cigré 32-Bus System}

Following the step-by-step method for obtaining the electrical distances between buses, discussed in Section II-A, the normalized electrical distances $D_{i j}$ between generator buses $i$ and all the buses $j$ are calculated. To avoid analyzing too many electrical distances between buses, a Matlab program is written that groups the buses according to their distances $D_{i j}$ (Table I). In Table I, columns 2, 3, 4, and 5 list the buses whose electrical distances with the generator buses of column 1 are within the ranges (a) $\mathrm{D}_{\mathrm{ij}} \leq 0.10$, (b) $0.10<\mathrm{D}_{\mathrm{ij}} \leq 0.20$, (c) $0.20<\mathrm{D}_{\mathrm{ij}} \leq 0.25$, and (d) $0.25<\mathrm{D}_{\mathrm{ij}} \leq 0.30$, respectively.

Considering the electrical distances obtained in Table I and the topology structure of the network, the Cigré 32 bus system can now be divided into five voltage-control areas, zone-1 to zone-5, as shown in Fig. 2. Evidently, the electrical distances between buses lying in different zones are higher, compared to the distances between buses in the same zone. It is shown in Fig. 2 that there are eight buses in zone-1, ten buses in zone-2, three buses in zone-3, eight buses in zone-4 and three buses in zone-5. Zone-3 and zone-5 are relatively small zones compared to the others. There are only two generators in zone- 3 and 


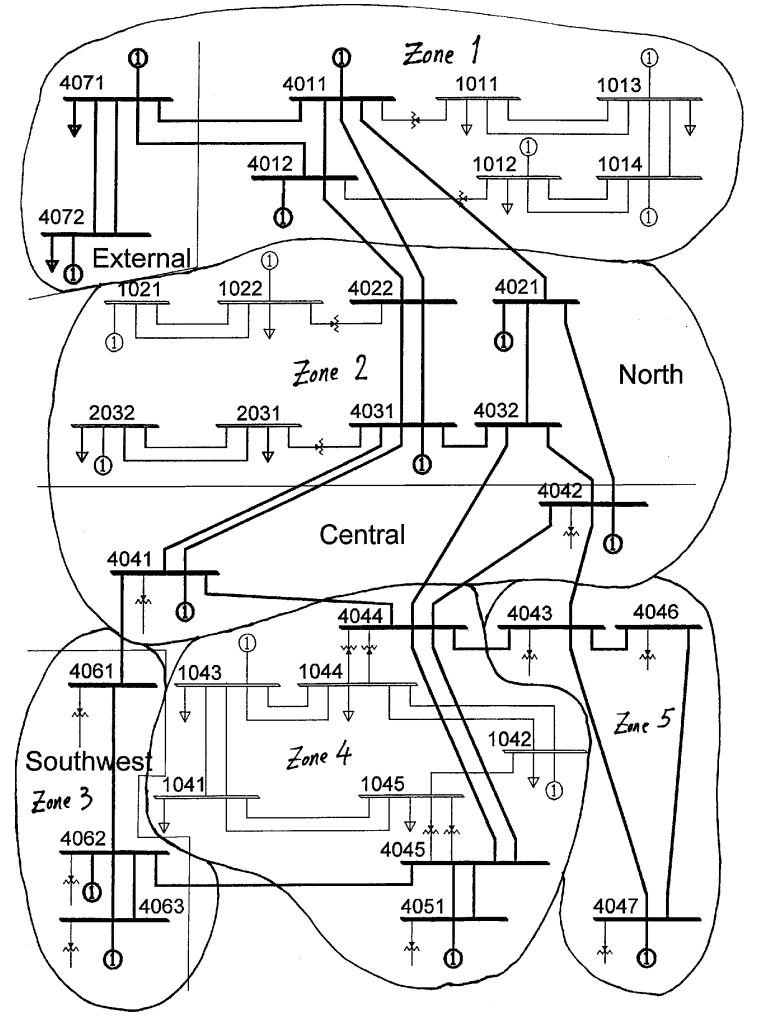

Fig. 2. Cigré 32-bus system: five voltage-control areas.

one in zone-5, while both zone- 1 and zone- 2 have seven generators each. It is difficult to organize a competitive market in a zone that has too few generators. After examining the electrical distances between the buses in zone- 3 and zone- 5 with buses in other zones, we find that zone- 3 and zone- 5 are closer to zone- 4 than to any other zone. Thus we combine zone- 3 , zone- 4 , and zone-5 and form one single zone. The new separation of voltage-control areas is shown in Fig. 3. In the new separation, we have Zone A, Zone B, and Zone $\mathrm{C}$.

Four study cases are now simulated to examine the proposed localized reactive power market.

- Case-0: simulates the reactive power market considering the whole system as one control area, and obtains one set of uniform market price for the whole system.

- Case-1: simulates the market considering three voltagecontrol areas as obtained earlier, and a set of uniform prices is determined separately for each area. Both Case-0 and Case- 1 use the same offer prices from generators. By comparing the results of Case- 0 and Case- 1 , we can observe the advantages of considering voltage-control areas for reactive power services.

- Case-2, Case-3: simulates gaming scenarios over Case-1 price offers, wherein the reactive power service provider at bus 4072 offers (a) $50 \%$ higher and (b) $60 \%$ higher prices, respectively, for its service.

\section{B. Case-0: System as Whole}

In Case-0, the uniform market prices $\rho_{0}, \rho_{1}, \rho_{2}$, and $\rho_{3}$ are obtained for the whole system. The purpose of simulating Case- 0 in this paper is to compare the results with Case-1, in which

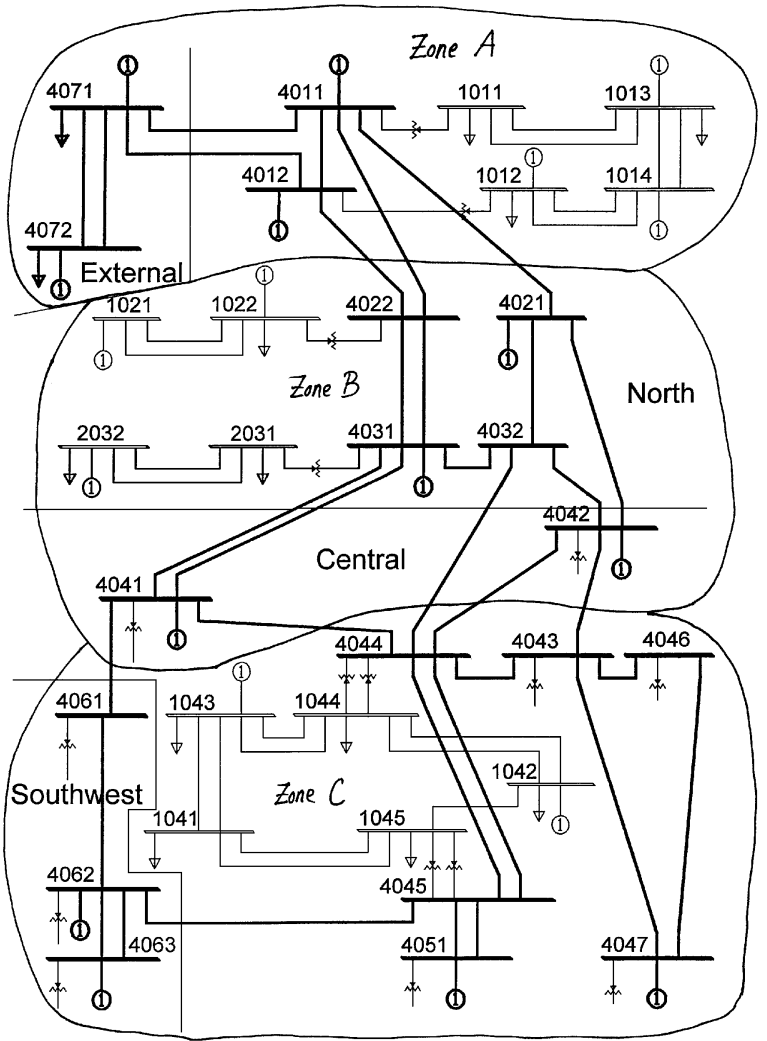

Fig. 3. Cigré 32-bus system: re-organization to three voltage-control areas.

uniform market prices are obtained separately for three voltagecontrol areas. The optimal reactive power contracts obtained in Case- 0 are provided in Table II.

In all the tables, the "**" denotes reactive support contracted in the range of opportunity costs, and a bold underscored offer price, (e.g., $\underline{\mathbf{0 . 9 6}}$ ) denotes that the particular offer is the market price setting offer. Note that market prices are determined by the highest selected offer in the system. We get availability price $\rho_{0}=0.96$, operation price $\rho_{2}=1.12$, and opportunity price $\rho_{3}=0.25$. Generators "4072," "2032," and "4011" are the corresponding price-setters. The under-excited operation price is $\rho_{1}=0$.

\section{Case-1: Considering Voltage-Control Areas}

The payment function (4), which calculates market prices for three zones separately, is now used to minimize the payment and hence settle the reactive power market. The optimal reactive power contracts and uniform market prices are provided in Table III.

In this case, market prices are obtained for three zones separately. In each zone, the market prices are determined from the highest accepted offer within that zone. From Table III, we note the following.

- The generator " 4072 " is selected as a price-setter of the availability price for all zones, the uniform availability price being $\rho_{0}=0.96$.

- No generator has been selected for providing reactive power services in zone $\mathrm{C}$.

- The under-excited operation price $\rho_{1}$ is zero since no generator is contracted to absorb reactive power. 
TABLE II

CASe 0: Reactive Power Contracts and Uniform PRICES

\begin{tabular}{|c|c|c|c|}
\hline & Bus & $\begin{array}{c}\text { Offer Prices } \\
\left(\mathbf{a}_{\mathbf{0}}, \mathbf{m}_{\mathbf{1}}, \mathbf{m}_{2}, \mathbf{m}_{3}\right) \\
\end{array}$ & $\begin{array}{c}\text { Reactive Contracts in } \\
\text { p.u.MVAr } \\
\end{array}$ \\
\hline \multirow{20}{*}{ 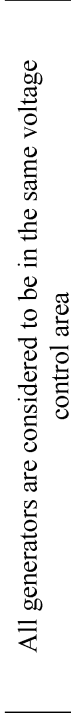 } & 4072 & $(\underline{\mathbf{0 . 9 6}}, 0.86,0.86,0.46)$ & 6.61 \\
\hline & 4071 & $(0.40,0.41,0.41,0.20)$ & 0 \\
\hline & 4011 & $(0.77,0.75,0.75, \underline{\mathbf{0 . 2 5}})$ & $3.77^{*}$ \\
\hline & 4012 & $(0.43,0.41,0.41,0.19)$ & $3.28^{*}$ \\
\hline & 1013 & $(0.50,0.54,0.54,0.28)$ & 1.25 \\
\hline & 1012 & $(0.42,0.42,0.42,0.17)$ & 0 \\
\hline & 1014 & $(0.69,0.68,0.68,0.39)$ & 1.66 \\
\hline & 4021 & $(0.91,1.29,1.29,0.70)$ & 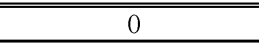 \\
\hline & 4031 & $(0.85,1.17,1.17,0.59)$ & 0 \\
\hline & 4042 & $(0.90,1.26,1.26,0.55)$ & 0 \\
\hline & 4041 & $(0.73,1.03,1.03,0.00)$ & 0 \\
\hline & 1021 & $(0.65,0.77,0.77,0.27)$ & 0 \\
\hline & 1022 & $(0.88,1.03,1.03,0.50)$ & 0.61 \\
\hline & 2032 & $(0.73,1.12, \underline{\mathbf{1 . 1 2}}, 0.40)$ & 1.74 \\
\hline & 4062 & $(0.76,1.05,1.05,0.48)$ & 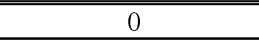 \\
\hline & 4063 & $(0.93,1.16,1.16,0.52)$ & 0 \\
\hline & 4051 & $(0.50,0.76,0.76,0.33)$ & 0 \\
\hline & 4047 & $(0.92,1.11,1.11,0.71)$ & 0 \\
\hline & 1043 & $(0.77,0.90,0.90,0.48)$ & 0 \\
\hline & 1042 & $(0.50,0.65,0.65,0.34)$ & 0 \\
\hline \multicolumn{4}{|c|}{ ISO's burden from these contracts } \\
\hline & \multicolumn{2}{|c|}{ Total Payment $\left(\mathrm{J}_{\mathrm{P}}\right), \$$} & 28.40 \\
\hline & \multicolumn{2}{|c|}{ Available Price, $\rho_{0}$} & 0.96 \\
\hline & \multicolumn{2}{|c|}{ Operation Price, $\rho_{1}$} & 0 \\
\hline & \multicolumn{2}{|c|}{ Operation Price, $\rho_{2}$} & 1.12 \\
\hline & \multicolumn{2}{|c|}{ Opportunity Price, $\rho_{3}$} & 0.25 \\
\hline
\end{tabular}

- For zone $\mathrm{A}, \rho_{2}=0.86$ and $\rho_{3}=0.19$; generators on buses "4072" and "4012" are the corresponding price-setters.

- For zone $\mathrm{B}, \rho_{2}=1.12$ and $\rho_{3}=0.50$; generators on buses "2032" and "1022" are the corresponding price-setters.

By comparing the results of Tables II and III, we have the following observations.

a) For zone $\mathrm{A}$, the uniform market prices applicable from Case- 0 are $\rho_{2}=1.12$ and $\rho_{3}=0.25$. These prices decrease to $\rho_{2}=0.86$ and $\rho_{3}=0.19$ in Case- 1 , when the market settlement is based on voltage-control areas.

b) The total payment to be made by the ISO to procure the reactive power services in Case-0 is $\$ 28.40$. This decreases to $\$ 23.77$ in Case-1 (16.3\% less payment burden on the ISO).

Thus, we note that both market prices and hence the total payment burden of the ISO to procure reactive power services are reduced after we settle the market with respect to voltage-control areas.

\section{Case-2 and Case-3: Gaming by Generator 4072}

In Case-2 and Case-3, we now increase the offer prices $m_{1}, m_{2}$, and $m_{3}$, from the generator at bus 4072 by $50 \%$ and $60 \%$ respectively over Case- 0 and Case- 1 prices. The reactive power procurement schemes obtained when minimizing the payment function (4) are provided in Table IV. In the table, the superscript 1 denotes that the particular offer is price setting offer in Case-1, superscript 2 denotes a price-setting offer in Case-2 and superscript 3 denotes price-setting offer in Case- 3.
TABLE III

CASE 1: Reactive POWER CONTRACTS AND ZONE-Wise PRICES

\begin{tabular}{|c|c|c|c|c|c|}
\hline & Bus & $\begin{array}{c}\text { Offer Prices } \\
\left(\mathbf{a}_{\mathbf{0}}, \mathbf{m}_{1}, \mathbf{m}_{2}, \mathbf{m}_{3}\right)\end{array}$ & \multicolumn{3}{|c|}{$\begin{array}{c}\text { Reactive Contracts in } \\
\text { p.u.MVAr }\end{array}$} \\
\hline \multirow{7}{*}{$\begin{array}{c}\text { Zone } \\
\text { A }\end{array}$} & 4072 & $(\underline{\mathbf{0 . 9 6}}, 0.86, \underline{\mathbf{0 . 8 6}}, 0.46)$ & \multicolumn{3}{|c|}{6.82} \\
\hline & 4071 & $(0.40,0.41,0.41,0.20)$ & \multicolumn{3}{|c|}{0} \\
\hline & 4011 & $(0.77,0.75,0.75,0.25)$ & \multicolumn{3}{|c|}{2.52} \\
\hline & 4012 & $(0.43,0.41,0.41, \mathbf{0 . 1 9})$ & \multicolumn{3}{|c|}{$3.28^{*}$} \\
\hline & 1013 & $(0.50,0.54,0.54,0.28)$ & \multicolumn{3}{|c|}{1.25} \\
\hline & 1012 & $(0.42,0.42,0.42,0.17)$ & \multicolumn{3}{|c|}{$2.78^{*}$} \\
\hline & 1014 & $(0.69,0.68,0.68,0.39)$ & \multicolumn{3}{|c|}{0} \\
\hline \multirow{7}{*}{$\begin{array}{l}\text { Zone } \\
\text { B }\end{array}$} & 4021 & $(0.91,1.29,1.29,0.70)$ & \multicolumn{3}{|c|}{0} \\
\hline & 4031 & $(0.85,1.17,1.17,0.59)$ & \multicolumn{3}{|c|}{0} \\
\hline & 4042 & $(0.90,1.26,1.26,0.55)$ & \multicolumn{3}{|c|}{0} \\
\hline & 4041 & $(0.73,1.03,1.03,0.00)$ & \multicolumn{3}{|c|}{0} \\
\hline & 1021 & $(0.65,0.77,0.77,0.27)$ & \multicolumn{3}{|c|}{0} \\
\hline & 1022 & $(0.88,1.03,1.03, \underline{\mathbf{0 . 5 0}})$ & \multicolumn{3}{|c|}{$0.91 *$} \\
\hline & 2032 & $(0.73,1.12, \underline{\mathbf{1 . 1 2}}, 0.40)$ & \multicolumn{3}{|c|}{1.68} \\
\hline & 4062 & $\begin{array}{ll}(0.76,1.05,1.05,0.48) \\
\end{array}$ & \multicolumn{3}{|c|}{ 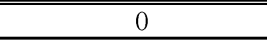 } \\
\hline & 4063 & $(0.93,1.16,1.16,0.52)$ & \multicolumn{3}{|c|}{0} \\
\hline Zone & 4051 & $(0.50,0.76,0.76,0.33)$ & \multicolumn{3}{|c|}{0} \\
\hline $\mathrm{C}$ & 4047 & $(0.92,1.11,1.11,0.71)$ & \multicolumn{3}{|c|}{0} \\
\hline & 1043 & $(0.77,0.90,0.90,0.48)$ & \multicolumn{3}{|c|}{0} \\
\hline & 1042 & $(0.50,0.65,0.65,0.34)$ & \multicolumn{3}{|c|}{0} \\
\hline \multicolumn{6}{|c|}{ ISO's burden from these contracts } \\
\hline \multicolumn{3}{|c|}{ Total Payment $\left(\mathrm{J}_{\mathrm{P}}\right), \$$} & \multicolumn{3}{|c|}{23.77} \\
\hline \multicolumn{3}{|c|}{ Zone } & $\mathrm{A}$ & $\mathrm{B}$ & $\mathrm{C}$ \\
\hline \multicolumn{3}{|c|}{ Available Price, $\rho_{0}$} & \multicolumn{3}{|c|}{0.96} \\
\hline & & ation Price, $\rho_{1}$ & \multicolumn{3}{|c|}{0} \\
\hline \multicolumn{3}{|c|}{ Operation Price, $\rho_{2}$} & 0.86 & 1.12 & 0 \\
\hline & & tunity Price, $\rho_{3}$ & 0.19 & 0.50 & 0 \\
\hline
\end{tabular}

TABLE IV

ReActive Power Contracts IN THREe CASES

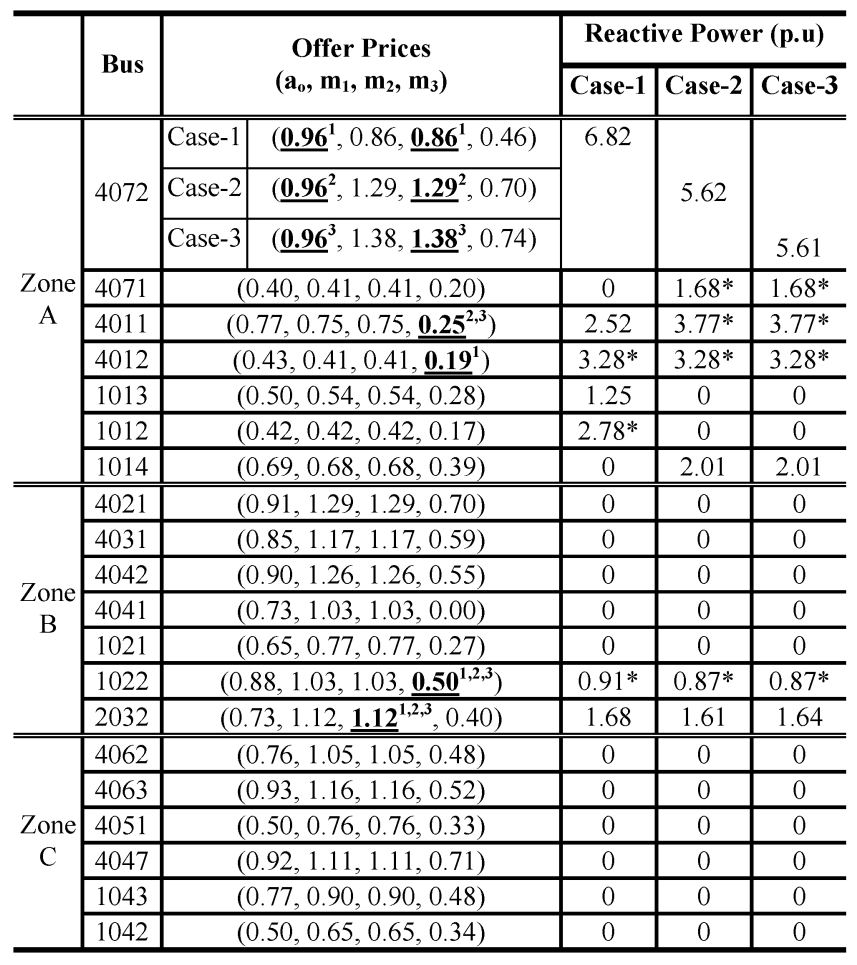

From Table IV, we can see that reactive power procurement schemes are almost unchanged in Zone B and Zone C, when the offer prices of 4072 (which is in Zone A) are increased. In Zone A, the generator at bus 4071 , which is the closest to 4072 , 
TABLE V

UnIForm MARKET PRICE COMPARISON IN THREE CASES

\begin{tabular}{|c|c|c|c|c|c|c|c|c|c|}
\hline & \multicolumn{3}{|c|}{ Case-1 } & \multicolumn{3}{|c|}{ Case-2 } & \multicolumn{3}{|c|}{ Case-3 } \\
\hline & $\begin{array}{c}\text { Zone } \\
\text { A }\end{array}$ & $\begin{array}{c}\text { Zone } \\
\text { B }\end{array}$ & $\begin{array}{c}\text { Zone } \\
\text { C }\end{array}$ & $\begin{array}{c}\text { Zone } \\
\text { A }\end{array}$ & $\begin{array}{c}\text { Zone } \\
\text { B }\end{array}$ & $\begin{array}{c}\text { Zone } \\
\text { C }\end{array}$ & $\begin{array}{c}\text { Zone } \\
\text { A }\end{array}$ & $\begin{array}{c}\text { Zone } \\
\text { B }\end{array}$ & $\begin{array}{c}\text { Zone } \\
\text { C }\end{array}$ \\
\hline Available Price, $\rho_{0}$ & \multicolumn{3}{|c|}{0.96} & \multicolumn{3}{|c|}{0.96} & \multicolumn{3}{|c|}{0.96} \\
\hline Operation Price, $\rho_{1}$ & \multicolumn{3}{|c|}{0} & \multicolumn{3}{|c|}{0} & \multicolumn{3}{|c|}{0} \\
\hline Operation Price, $\rho_{2}$ & 0.86 & 1.12 & 0 & 1.29 & 1.12 & 0 & 1.38 & 1.12 & 0 \\
\hline Opportunity Price, $\rho_{3}$ & 0.19 & 0.50 & 0 & 0.25 & 0.50 & 0 & 0.25 & 0.50 & 0 \\
\hline
\end{tabular}

is selected to provide reactive power when the offer prices of 4072 increase.

The uniform market prices obtained in three cases are compared in Table V. We can see that the market prices of Zone $\mathrm{B}$ and Zone $\mathrm{C}$ remain unchanged even after a $60 \%$ increase in offer prices of 4072 . This shows that any attempt to game the prices by a market power holder in one zone will not affect the market prices of other zones, if market settlement is based on voltage-control areas.

\section{CONCLUding REMARKS}

This paper attempts to develop a competitive market for reactive power services based on localized voltage-control areas. The market is based on four components of price offers from generators. The ISO settles the market for individual voltagecontrol areas while minimizing the gross payment to be made to procure the services. The concept of electrical distance has been used in the paper to separate out from the Cigré 32-bus system, three voltage-control areas. Reactive power market prices for three voltage-control areas are obtained by the ISO based on the price offers. From the analysis of the results, we have the following conclusions.

- Considering the reactive power market to be localized within a voltage-control area will reduce the payment burden of the ISO in procurement of reactive power services in the system.

- The prices of reactive power service in those areas with lower price offers remain lower than the prices in the areas with higher price offers. This means that considering localized markets according to voltage-control areas is more reasonable in a deregulated power system compared to considering one uniform price for the whole system.

- In the localized voltage-control area based reactive power market, if a generator from one control area attempts to game the price, the market prices in other voltage-control areas will not be affected.

- Generator gaming in one area will not affect other areas, this can prove that separating voltage-control areas will help to improve the fairness of market in economic views. On the other hand, it can also prove that the method used to separate voltage-control areas is effective.

\section{REFERENCES}

[1] New York Independent System Operator Ancillary Services Manual, 1999.

[2] National Electricity Market Ancillary Services, National Electricity Market Management Company, Nov. 1999.

[3] R. Hirvonen, R. Beune, L. Mogridge, R. Martinez, K. Roudén, and O Vatshelle, "Is There a Market for Reactive Power Services-Possibilities and Problems," CIGRÉ Session 2000, Paris, France, CIGRÉ Paper $39-213,2000$.
[4] J. Zhong and K. Bhattacharya, "Reactive power management in deregulated power systems-A review," in Proc. IEEE Power Engineering Society Winter Meeting, vol. 2, 2002, pp. 1287-1292.

[5] S. Hao and A. Papalexopoulos, "Reactive power pricing and management," IEEE Trans. Power Syst., pp. 95-104, Feb. 1997.

[6] K. Bhattacharya and J. Zhong, "Reactive power as an ancillary service," IEEE Trans. Power Syst., vol. 16, pp. 294-300, May 2001.

[7] J. Zhong and K. Bhattacharya, "Toward a competitive market for reactive power," IEEE Trans. Power Syst., vol. 17, pp. 1206-1215, Nov. 2002.

[8] B. A. Schlueter, S. Liu, and K. Ben-Kilani, "Justification of the voltage stability security assessment and diagnostic procedure using a bifurcation subsystem method," IEEE Trans. Power Syst., vol. 15, pp. 1105-1111, Aug. 2000.

[9] P. Lagonotte, J. C. Sabonnadiere, J. Y. Leost, and J. P. Paul, "Structural analysis of the electrical system: Application to secondary voltage control in France," IEEE Trans. Power Syst., vol. 4, pp. 479-486, May 1989.

[10] H. Liu, A. Bose, and V. Venkatasubramanian, "A fast voltage security assessment method using adaptive bounding," IEEE Trans. Power Syst., vol. 15 , pp. -, Aug. 2000 .

[11] E. Nobile and A. Bose, "A new scheme for voltage control in a competitive ancillary service market," in Proc. 14th Power Systems Computation Conf., Sevilla, Spain, June 2002.

[12] J. Zhong, "Design of Ancillary Service Markets: Reactive Power and Frequency Regulation," Chalmers Univ. Technol., Gothenburg, Sweden, Tech. Rep. 392L, May 2001.

Jin Zhong (S'03) received the B.Sc. (Eng.) degree from Tsinghua University, Beijing, China, in 1995 and the M.Sc. (Eng.) degree from the Electric Power Research Institute, Beijing, in 1998, and the Ph.D. degree from Chalmers University of Technology, Gothenburg, Sweden, in 2003.

She worked as a Researcher at the Electric Power Research Institute, Beijing, during 1998-1999. In 2002, she spent five months as a Visiting Scholar at Washington State University, Pullman. Currently, she is an Assistant Professor in the Department of Electrical and Electronic Engineering at the University of Hong Kong. Her areas of interest are electricity sector deregulation and ancillary service pricing.

Emilia Nobile (M'03) received the Laurea degree (Hons.) from the Politecnico di Bari, Bari, Italy, in 1997, and the Ph.D. degree in electrical engineering from Washington State University, Pullman, in 2002.

In 1998, she was awarded a scholarship from Politecnico di Bari to spend one year as research scholar at the School of Electrical Engineering and Computer Science, Washington State University. Currently, she is a Power Systems Consultant at the European office of Shaw Power Technologies International, Knutsford, U.K.

Anjan Bose (M'68-SM'77-F'89) received the B.Tech. (Hons.) degree from the Indian Institute of Technology, Kharagpur, in 1967, the M.S. degree from the University of California, Berkeley, in 1968, and the Ph.D. degree from Iowa State University, Ames, in 1974.

He has previously worked for the Consolidated Edison Company of New York (1968-1970), the IBM Scientific Center, Palo Alto, CA (1974-1975), Clarkson University (1975-1976), Control Data Corporation (1976-1981), and Arizona State University (1981-1993). At present, he is the Distinguished Professor in Power Engineering and Dean of the College of Engineering and Architecture at Washington State University, Pullman.

Dr. Bose was elected as a member of the U.S. National Academy of Engineering in 2003.

Kankar Bhattacharya (M'95-SM'01) received the Ph.D. degree in electrical engineering from the Indian Institute of Technology, New Delhi, in 1993.

He was with the Faculty of Indira Gandhi Institute of Development Research, Bombay, India, during 1993-1998, and then the Department of Electric Power Engineering, Chalmers University of Technology, Gothenburg, Sweden, during 1998-2002. Since January 2003, he has joined the Department of Electrical and Computer Engineering, University of Waterloo, ON, Canada, as an Associate Professor. His research interests are in power system dynamics, stability and control, economic operations planning, electricity pricing and electric utility deregulation.

Dr. Bhattacharya received the 2001 Gunnar Engström Foundation Prize from ABB Sweden for his work on power system economics and deregulation issues. 